\title{
A BUSINESS RULE ENGINE APPLIED TO EGOVERNMENT SERVICES INTEGRATION
}

\author{
Aqueo Kamada ${ }^{1,2}$ and Manuel Mendes ${ }^{2,3}$ \\ ${ }^{1}$ CenPRA, Rod. Dom Pedro I, km 143.6, 13082-120, Campinas, SP, Brazil; ${ }^{2}$ Unicamp, Cidade \\ Universitária "Zeferino Vaz", 13083-970, Campinas, SP, Brazil; 'Unisantos, Rua Dr. \\ Carvalho de Mendonça, 144, 11070-906 Santos, SP, Brazil
}

\begin{abstract}
A great part of applications is increasingly based on the Internet and the needs for changes in these applications happen in shorter and shorter periods. Companies, governments and people who wait for almost instantaneous implementations of those changes stimulate this scenario of high demand for changes. In the context of these fast changes, the approaches based on business rules are aiming for an implementation of solutions that are more flexible to changes and that are in a language easily understandable to business people in a business perspective. This article presents a proposal of a Business Rule Engine customized for e-Government applications, considering the componentization and/or Web "servicification" of life event applications with access to several legacy back office systems. The proposed Business Rule Engine is in conformance with the Business Semantics of Business Rules (BSBR) meta-model, which is in its final phase of specification by OMG.
\end{abstract}

Key words: Business Rule, Business Rule Engine, e-Government, Web Services and business component.

\section{INTRODUCTION}

Modern companies are increasingly adopting new models of business processes to improve the competitiveness in a market that expects a fast reaction to changes according to customers' demands. These modern companies have noticed the inherent conflict between the fluidity and agility they want their businesses to accomplish and the rigidity and control in which their systems operate. The incompatibility among agile businesses and 
rigid systems annuls the efforts indeed to change the business and quickly to capitalize in business opportunities ${ }^{1}$. It is thus verified, that, whether a company is aggressive or conservative in the adoption of changes, the changes are inevitable and they happen in a continuous and relentless way. Therefore, companies that don't get to answer with agility to the changes of the business rules lose in competitiveness.

Business rules technologies are becoming very popular in many groups of companies, such as, financial and insurance groups, which are using some form of rule engine. According to a Gartner study ${ }^{2}$, the average ROI for a rules implementation across all industries is a conservative $10 \%$ to $15 \%$. Another prominent factor are BPM tools (Business Process Management), most of which are based on rules. Many rules based process initiatives are user driven rather than technology driven. Users are initiating projects to define business vocabularies and business rule definition rather than these initiatives being forced upon them by the IT groups ${ }^{3}$.

Another issue strongly related to business rules is knowledge management $(\mathrm{KM})$. Successful initiatives in $\mathrm{KM}$ can be found in call centers and help desks and new applications with high potential to benefit of KM systems are Web applications and self-service systems. These applications should have well-structured dialogues, presupposing environment where the human intervention needs to be minimum and everything is subject to fast changes ${ }^{4}$. All the dialogue characteristics could be easily treated as business rules, once they represent the knowledge of a company that can be codified. Therefore, there is a great opportunity to do the connection between business rules and $\mathrm{KM}$.

The main challenges in business rules management can be summarized in the following topics:

1. It is difficult to capture and formalize business rules that were "lost" in the specifications of requirements, use cases. For example this happens in the extraction of business rules starting from UML notations, such as pre-conditions, pos-conditions, basic and alternative flows (operation rules) of use cases; OCL restrictions (restriction rules); and data and derived attributes (derivation rules),

2. Business rules may be related with several use cases. For example, a rule that says "any transaction with value higher than $\$ 10.000,00$ must be reported to the government" can be related with several use cases, such as "doing a deposit", "doing a withdrawal", etc.

3. Weakness in the combined execution of business rules that contemplate the control and relationships aspects among rules, and considering the components that implement specific logics of business. It is necessary to create mechanisms that take into account the existence of many legacy applications, with quite stable portions and that it is possible the use of 
these legacy applications through the componentization or "servicification" of them.

There are several business rules products ${ }^{5,6,7}$ that are well established and demonstrate the effectiveness of their use, but there is not a definitive guide, up to now, for an effective management of Business Rules. Ron Ross ${ }^{8}$, who is considered the father of the theory of Business Rules, asserts that changes in the businesses constantly happen, in small or large scale, and it is rare to find a software product that can be changed easily once implemented. He also affirms that the lack of ability and flexibility to change increases significantly business' costs. He concludes that the "software needs to be the agent of the change, not the enemy of the change." Thus, it seems that, without an approach to identify the rules in the terminology of businesses and a way to translate these rules in computerized systems, with a minimum or no programming effort, it may be impossible to reach the goal, of being at the same time more precise, faster and cheaper.

The Business Rules can bring the benefits of the agility, but their effective use requires urgently supporting architectures. One of the solutions for this challenge is the development of business rules interpreters (Business Rules Engine, BRE) based on the variability of rules that, in its turn, has implications in the architecture of the rules.

In this paper, a business rule engine is proposed, one which makes the combination of control aspects of business rules with the execution of Web services or components that implement specific applications already developed in the context of governments. Therefore this proposal considers the existence of business rules, representing portions that are dynamic and sensitive to the market changes, requiring quick answer to these changes. It also takes into account the existence of a large number of government applications, with quite stable portions and, usually, of difficult maintenance, which have to be combined with other portions that are pretty volatile. The chosen scenario to exercise the ideas behind the proposed business rules engine is the same one used in the context of the eGOIA project ${ }^{9}$, which is the civil identification public scenery from São Paulo State, Brazil. eGOIA is a 3 years project partially funded by the European Union through the @LIS program $^{10}$.

This paper is organized as follows. Section 2 presents some issues related to business rules, types, processes, standards and tools. Section 3 presents an e-Government scenario to exercise the combined execution of business rules and Web services. In section 4 we introduce the execution and architecture of integrating business rule engine and the business vocabulary and rules repository complemented by Web services infrastructure. Section 5 presents the conclusion of the paper. 


\section{BUSINESS RULES CONCEPTS AND STANDARDIZATION}

This section presents some discussion on business rules concepts, types, and considerations for separating rules from processes, standards and tools.

\subsection{Business Rule Definitions}

There are several business rule definitions, many of them very similar and using almost the same keywords in its definition. We present here an adapted one from the Business Rules Group, which considers two definitions for business rules ${ }^{11}$ : one that represents the business perspective and another that represents the perspective of Information Technology (IT).

From the business perspective, a business rule is a premise that guides the business' behavior, in defense of a business policy that was formulated with regard to an opportunity, a threat, a force, or a weakness.

From the IT perspective, a business rule is a declaration that defines or restricts an aspect of the business or, in other words, defines the structure of the business and controls the behavior of the business.

In the context of our proposal we define a business rule as "an enterprise statement that defines or constrains some aspects of the business, according to the enterprise's policies and, therefore, influences the behavior of the business".

\subsection{Basic Types of Business Rules}

Business rules can be classified in several ways ${ }^{12}$, among which the following seem the most relevant ${ }^{11}$ :

- Structural business rules prescribe criteria for how the business chooses to organize (i.e., structure) the things it deals with by expressing a necessity or a possibility. Such rules express criteria for correct decisions, derivations or business computations. For example, the following rule expresses a necessity: The Customer has at least one of the following: a Rental Reservation, an in-progress Rental or a Rental completed in the past 5 years.

- Operative business rules are those that govern the conduct of business activities by expressing an obligation or prohibition. In contrast to structural rules, operative rules are ones that can be directly violated by people involved in the affairs of the business. For example, the following rule expresses a prohibition: "A Customer who appears intoxicated must not be given possession of a Rental Car". 


\subsection{Rules and Process}

There is a lot of discussion concerning to the nature of a process and of a rule. In part, this is due to the division of the market around rules driven by BPM applications (Business Process Management) and pure rules engines. One way to look at it is that it potentially removes all the decision diamonds of the process' flows and replaces them with declarative, sharable business rules definitions ${ }^{13}$. Yet Zachman ${ }^{14}$ considered that, in the past, the reason for separating data and process was that data definitions changed more slowly than processes, and that the same argument can be applied for processes and rules, making another interesting observation. Thus, the idea is that the business processes are relatively static and only the rules are dynamic. Sinur's study ${ }^{15}$ showed that, in practice, close to $65 \%$ of business rules were actually relatively static, while $35 \%$ were very volatile. Of these volatile rules, only half were typically satisfactory to be updated directly by the business users.

\subsection{Business Rules Standards and Tools}

A lot of research and standardization in Business Rules are being developed. OMG is specifying the Business Semantics of Business Rules $(B S B R)^{11,16}$. BRG created the BR Manifesto ${ }^{17}$ and $\mathrm{W} 3 \mathrm{C}$ is specifying the Semantic Web Rule Language (SWRL) ${ }^{18}$.

Figure 1 display the evolution of standards that can be used to represent business rules or that are converging to represent them.

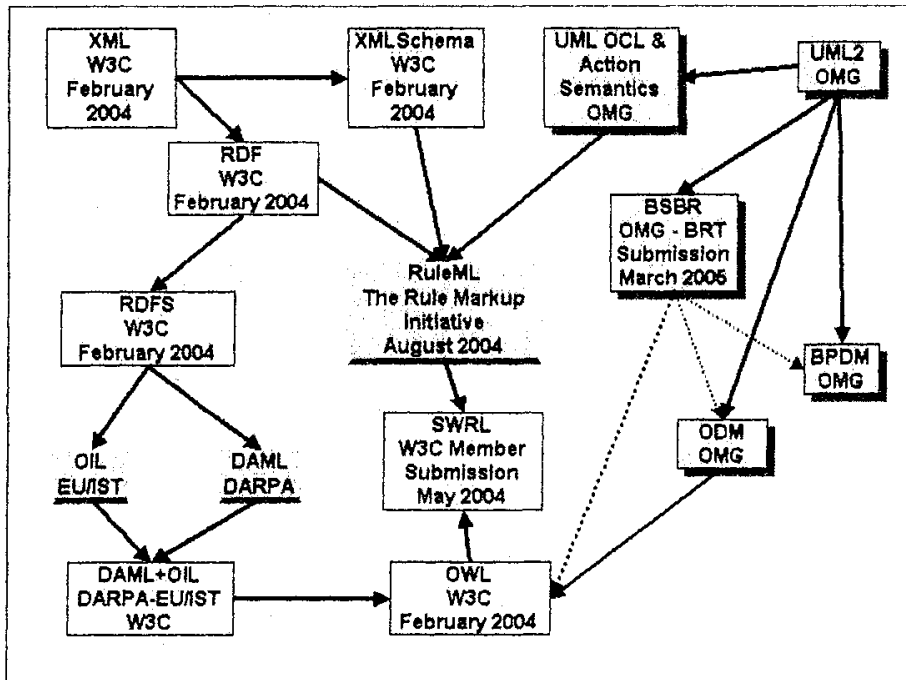

Figure 1. XML Standards towards Business Rules 


\subsubsection{The BSBR Meta-model}

Due to the lack of a consensus to define business rules, OMG published a request for proposal (RFP) ${ }^{16}$ requesting proposals to present solutions to allow business people to define the policies and the rules that run their businesses in their own language, in terms of the artifacts with which they accomplish their businesses. Besides that the other objective is to capture those rules in a clear way, not ambiguous and quickly transformable in other representations, such as the representations for the business people, for the software engineers, and for the automated systems of business rules execution. This RFP requested proposals for (i) a MOF metamodel for the specification of business rules for business people; (ii) a metamodel for the capture of vocabularies and definitions of the conditions used in business rules; (iii) an XML representation of business rules and vocabularies based on XMI in order to allow rules and vocabulary interoperability among software tools that manage business rules.

The resulting BSBR Metamodel is intended not for business people but for software engineers that build tools for business people.

In this paper, the following convention is used, adapted from $B S B R^{11}$, for the representation of facts and business rules:

- italics - key words of the rule or fact

- bold - verbs or actions

- underlined bold - community vocabulary terms

Following there are some examples of structural and operative business rules defined according to this metamodel.

- structural business rule: $A$ rental always has exactly one return branch.

- operative business rule: Each driver of a rental must be $a$ qualified driver.

\subsubsection{Business Rules Tools}

The main commercial tools for business rules execution are Blaze Advisor ${ }^{5}$, CleverPath Aion ${ }^{6}$, BRS RuleTrack ${ }^{7}$, Haley ${ }^{19}$, Jrules $^{20}$, VALENS ${ }^{21}$, Corticon Decision Management ${ }^{22}$ and Jess ${ }^{23}$. The main open source business rules engines are OFBiz Rule Engine ${ }^{24}$, Mandarax $^{25}$, Drools $^{26}$ and Jena $2^{27}$.

\section{BUSINESS RULES USAGE SCENARIO}

This section presents an e-Government scenario to exercise the execution of business rules. This scenario is inserted in the context of a Brazilian eGovernment applications environment, in the São Paulo State ${ }^{9}$. To simplify, 
the scenario considers only some services related to the civil identification community and the specific life event of a citizen that had his/her identification card (Id Card) lost or stolen..

\subsection{Scenario Description}

When a citizen has his/her Id Card stolen or lost he/she will go to a Government Portal in order to register the incident in an official form called BO (Bulletin of Occurrence) provided by a government agency through a back office system called BO System. Then, the Id Card Cancellation service provided by another back office system called Civil Identification System is accomplished to avoid the improper use of the Id Card. After that, the citizen can request for an Id Card replacement (new issue), provided by these two legacy systems plus a set of complimentary legacy systems. The issuing of new replacement cards may also be necessary for people who are getting older or when people may not be recognized because of the old document's photograph, or even due to name change by marriage or even signature change.

\subsection{Business Rules for Civil Identification Community}

Adherent to the concept of rule set as a "collection of business rules grouped together for some purpose", included in the proposed BSBR metamode $^{11}$, are the defined rule sets related to the Civil Identification Community.

In some of the business rules the actions (italics parenthesized texts) that could be executed by the components or Web services are included. The execution of the business rules associated with the Id Card Cancellation service bases on the following facts (understood as atomic units that communicates something) stored in the Business Vocabulary and Rule Repository (BVRR, proposed in this paper and detailed in the next section).

- An Identification Card identifies a Citizen.

- An Id Card is an Identification Card.

- An Incident Report registers an Incident.

- A $\underline{B O}$ is an Incident Report.

The rule sets, contained in the Repository, related to the Id Card Cancellation service could be formalized like these:

Rule Set 1 - Rules to Id Card Cancellation

- Rule 1.1 - An Id Card must be cancelled (Update_Id_Card_Status) only if one of the following facts is true: 
- The citizen lost his/her Id Card and the citizen registered a $\underline{\text { BO }}$ and the Id Card is registered

- The citizen lost his/her Id Card and the citizen registered a $\underline{\mathbf{B O}}$ and the Id Card is pre-registered

Rule Set 2 - Rules to register $\underline{B O}$

- Rule 2.1 - A citizen must register a $\underline{\mathrm{BO}}$ (BO_Register) only if one of the following facts is true:

- The citizen lost his/her Id Card

- The citizen has his/her Id Card stolen

- Rule 2.2 - A BO is registered if a BO Data exists electronically (ReceiveBO).

Rule Set 3 - Rules to register or pre-register Id Card

- Rule 3.1 - An Id Card is registered if the Id Card Data exists electronically (Retrieve_Id_Card_Data).

- Rule 3.2 - An Id Card must be pre-registered electronically using a BO Data (PreRegister_Id_Card) only if the Id Card is not registered.

Rule Set 4 - Rules to log information

- Rule 4.1 - A lost Id Card with a registered BO whose BO Data is different from Id Card Data must have this information (differences) logged (Log_CancellationService_Result).

- Rule 4.2 - All service actions must have their information logged (Log_CancellationService_Result).

The rule set for requesting an Id Card Replacement Issue service is:

Rule Set 5- Rules to request Id Card Replacement

- Rule 5.1 - A Citizen should request an Id Card replacement issue (Request_IdCard_Replacement) only if at least one of the following facts is true:

- The Citizen lost his/her Id Card and the Citizen registered a BO and the Id Card has been cancelled

- The Citizen wants to change his/her photograph

- The Citizen wants to change his/her name

- The Citizen wants to change his/her signature

\subsection{Discovering the user's desires}

Imagine a Web Portal that is based on life events that begins to treat the citizen's desires with orientations, such as (orientation 1) - "Please, enter a short sentence indicating what happened to you or what do you want to do." 
Assuming that the citizen enters: "I lost my identification card", the system can then provide a new orientation, such as (orientation 2) "Please, enter the number of your identification card:..............". Thus, with the provided Id Card number and a few interactions the system discovers that the citizen's desire and reason can be resumed to "the request for a new issue of an identification card, due to the loss of the citizen's Id card".

Although the strategies to discover user's desire are very interesting, they are outside the scope of this article.

\subsection{Discovering the facts and the business rules}

After the citizen's desires have been discovered the Business Rule Engine (BRE) generates the fact "citizen lost Id Card" in the Repository. The BRE begins its job by searching for facts and business rules. It discovers that the main rule (Rule 5.1) related to the citizen's desire is included in the rule set "Rules to request Id Card Replacement". As it can be seen in this main rule, the dispatching of the action (Request_IdCard_Replacement) has as pre-condition the facts "Citizen lost Id Card" and "Citizen registered BO" and "Id Card is cancelled". To simplify, it is assumed that the Citizen does not want to change anything, although he/she could change the photograph, name and signature.

All the facts and business rules that have direct or indirect relationship with the reason "loss of the identification card" must be considered, which means all the facts and rule sets listed in the subsection 3.2.

\subsection{Executing Business Rules combined with legacy components}

This section intends to show how actions should be dispatched when a business rule is in execution. In general these actions are implemented as Web services and/or components wrapping accesses to legacy applications.

When searching the BVRR, the BRE discovers that it is necessary to execute actions in order to generate the facts "The citizen registered a $\underline{B O}^{\text {" }}$ and "The Id Card is cancelled".

Based on the Rule 2.1, an action (BO_Register) should be dispatched, since the condition "The citizen lost his/her Id Card" was satisfied. Assuming that the citizen accepted and supplied the necessary data to register a $\mathrm{BO}$, the $\mathrm{BO}$ data begins to exist electronically and the fact "The

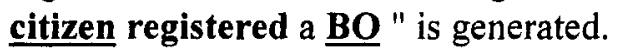

As it can be seen in Rule 1.1, to cancel an Id Card it is necessary to have one of the conditions "The Id Card is registered" or "The Id Card is 
pre-registered" satisfied. Thus, if the action (Retrieve_Id_Card_Data) of Rule 3.1 returns with success, i.e., The Id Card is electronically registered; the fact "The Id Card is registered" is generated. On the other hand, if the action (Retrieve_Id_Card_Data) returns unsuccessfully, i.e., Id Card is not electronically registered, it is assumed, by Rule 3.2 of the same rule set, that the Id Card needs to be pre-registered. The action (PreRegister_Id_Card) executed successfully generates the fact "The Id Card is pre-registered".

At this point, the successful execution of the action (Update_Id_Card_Status) generates the fact "The Id Card is cancelled".

Returning to Rule 5.1, once all of the pre-conditions are satisfied the action (Request_IdCard_Replacement) is dispatched to begin the process of requesting an Id Card replacement issue.

At the end of the accomplishment of the business service, the action (Log_CancellationService_Result) will be dispatched by Rule 4.2, to register all of the executed actions.

\section{BUSINESS RULES EXECUTION ARCHITECTURE}

This section introduces the architecture of execution of business rules, showing some details of how the difficulties and weaknesses in business rules are treated.

\subsection{The Architecture Modules}

Figure 2 presents the Business Rule Server composed by the Business Rule Engine (BRE) and by the Business Vocabulary and Rule Repository (BVRR).

The BRE gets from Service Scope Bounder the service profile and from BVRR all the rule sets associated to the service, then it executes the business rules found and finally returns the result to the service.

These modules are basic parts common to many of the proposals of business rules execution architectures ${ }^{28}$. As it is proposed in the Figure, to execute the business rules, BRE cooperates with Web Services Infrastructure (WSI), leaning on specific Web Service (WS) or components stored in the BCR. These WS or components implement specific logics and procedures of the business that are less susceptible of changes then the rules. Therefore, BRE makes the combination of the business rules execution control aspects with the execution of WS or component that implement specific logics of business. This approach, with the support of WSI or BCR, takes into account 
the existence of applications already developed (legacy), with quite stable portions and, usually, of difficult maintenance. Thus, it takes into account the possible use of these legacy applications through its Web "servicification" or "componentization" to facilitate the integration process in the phases of design and execution of business rules. From the BRE viewpoint, given a description of the WS or component, it is considered that WSI or BCR will return the URL of the WS or component. From now on we will only refer to WSI even though the same can be applied to BCR.

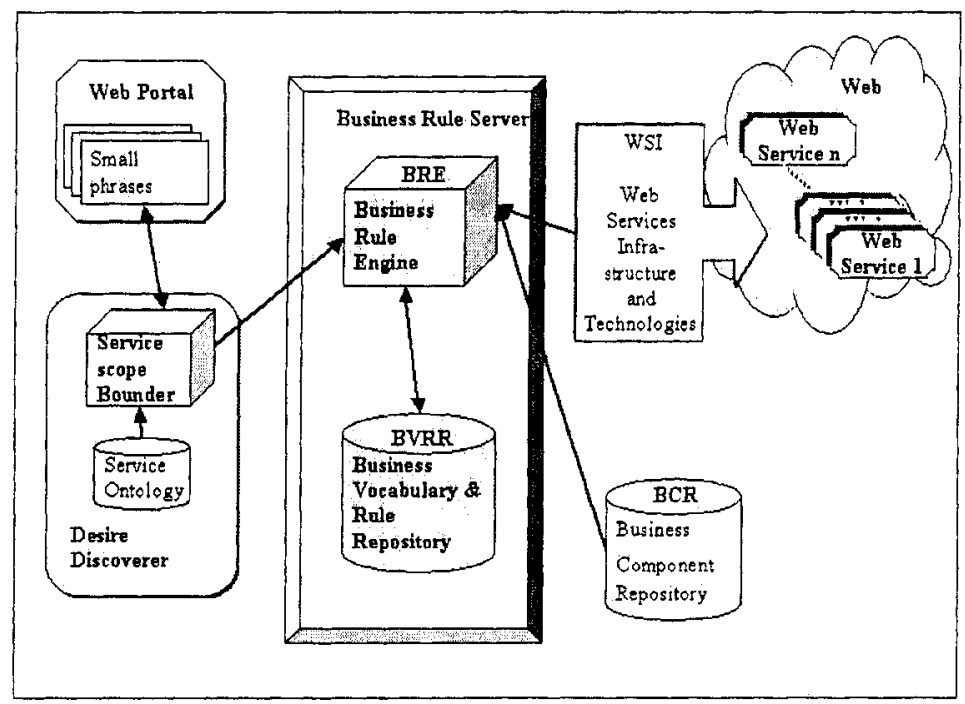

Figure 2. Business Rule Execution Architecture

\subsection{The Interaction between Modules}

The sequence diagram in the Figure 3 shows the interaction among the modules of the architecture. The context of the Civil Identification community is considered to show this interaction. Thus, the service could be a "request for a replacement issue of an identification card 123".

The Service Scope Bounder calls the BRE passing as a parameter to the Service profile. The Service profile contains all the properties needed to execute the service, such as, service identifier, citizen data, Id Card number, reason, etc. The BRE gets from the BVRR the rule sets associated with the service. For each business rule in the rule sets, the BRE also gets from the WSI all the WS URLs needed by the business rules. These WS will be dispatched by the business rule during its execution. The first business rule that will be considered for execution is the one that has the citizen's desire as 
an action, which is the Rule 5.1. Considering that, before dispatching the action (Request_IdCard_Replacement), the pre-conditions of that rule have to be satisfied, the rule is stacked, and other rules are executed. One of these rules could be Rule 2.1, whose execution could generate the fact "The citizen registered a BO". And, thus, successively the BRE will execute the rules in order to satisfy all the pre-conditions.

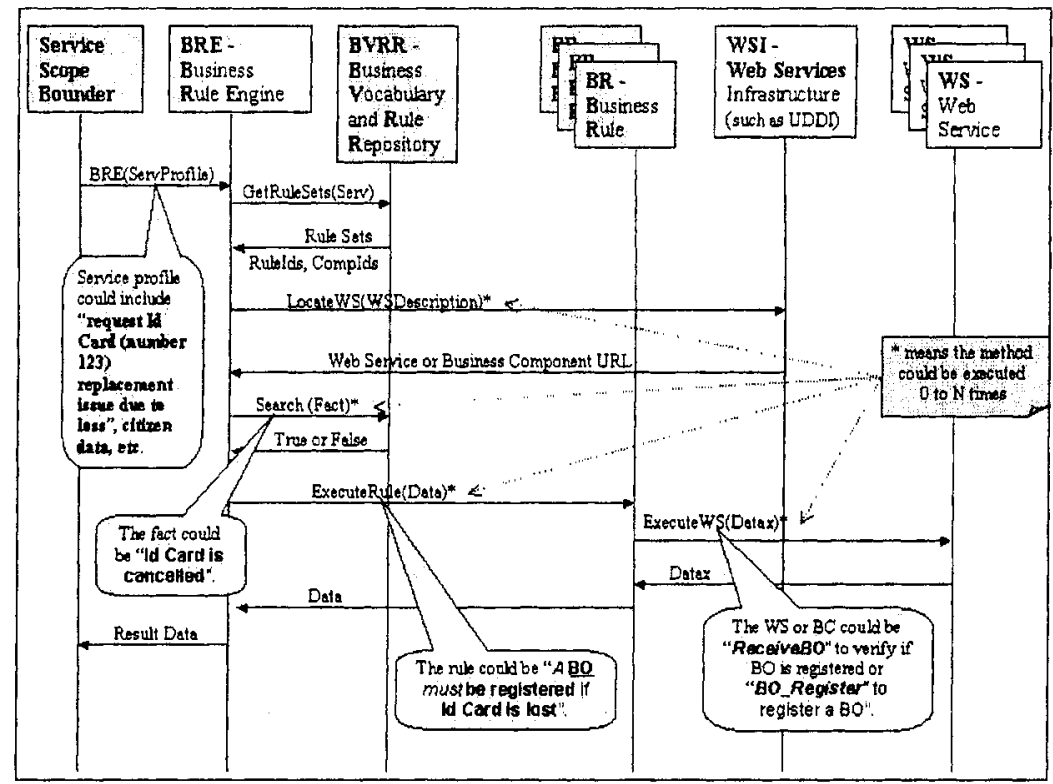

Figure 3 Sequence Diagram for Business Rules Execution.

\subsection{The Architecture Repositories}

This section describes the repositories of the proposed architecture.

\subsubsection{BVRR - Business Vocabulary and Rule Repository}

BVRR is a repository that defines terms, facts and business rules of specific application domains or that make sense for a community's user. It also defines the relationships and existent associations among these elements. Examples of business terms related to the civil identification application domain that could be stored in BVRR, are: Identification Card, Id Card, Id Card loss, Id Card replacement issue, Cancellation of Id Card, BO, Bulletin of Occurrence, Service Tax Payment, etc. Examples of facts in BVRR are: the BO is registered, the Id Card is cancelled, the Id Card is registered, etc. Examples of business questions/decisions and their respective 
business rules expressed in business people language and their possible formalizations are listed in Table 1.

Table 1. Examples of Business Rules associated to the Id Card cancellation.

\begin{tabular}{|c|c|c|}
\hline Decisions & $\begin{array}{l}\text { Business Rules for business } \\
\text { people }\end{array}$ & Pos \\
\hline Is th & $\begin{array}{l}\text { When an Id Card is lost it is } \\
\text { necessary to register a BO. }\end{array}$ & $\begin{array}{l}\text { e registered if an } \\
\text { it }\end{array}$ \\
\hline $\begin{array}{l}\text { Is the Id Card } \\
\text { canceled? }\end{array}$ & A lost Id Card must be canceled. & $\begin{array}{l}\text { An Id Card must be cancelled } \\
\text { if the Id Card is lost }\end{array}$ \\
\hline $\begin{array}{l}\text { Is the Id Card pre- } \\
\text { registered } \\
\text { electronically? }\end{array}$ & $\begin{array}{l}\text { An Id Card not electronically } \\
\text { registered should be pre-registered } \\
\text { electronically with BO data. }\end{array}$ & $\begin{array}{l}\text { An Id Card must be pre- } \\
\text { registered electronically with } \\
\text { BO Data }\end{array}$ \\
\hline $\begin{array}{l}\text { Does anybody need } \\
\text { to be notified about } \\
\text { the system's faults? }\end{array}$ & $\begin{array}{l}\text { All system failure should be } \\
\text { notified to a supervisor by e-mail }\end{array}$ & $\begin{array}{l}\text { All system failure must have } \\
\text { the information sent to the } \\
\text { supervisor bye-mail }\end{array}$ \\
\hline
\end{tabular}

\subsubsection{WSI - Web Services Infrastructure (or BCR - Business Component Repository)}

WSI is an infrastructure that provides functionalities, among other things, to locate WSs and return its URLs. BCR is a repository of basic software components. These WSs and basic components are in most of the cases encapsulation of application portions or services provided by legacy applications. Descriptions of some government's components that could be stored in BCR or wrapped as WSs are listed in Table 2.

Table 2. Government Web Services (or Business Component) examples

\begin{tabular}{ll}
\hline Web Service & Description \\
\hline BORegister & Register a BO \\
IdCardStatusUpdate & Update the Id Card Status in the Civil Identification system. \\
IdCardStatusQuery & Query Id Card Status in the Civil Identification system database. \\
BODataGet & Get BO Data from BO legacy system database. \\
IdDataGet & Get Id Card Data from Civil Identification legacy system database. \\
IdPreRegister & Accomplish the Id Card pre-registration on the Civil Identification \\
& system. \\
GuideGet & Get service guide data from Service Guide System.
\end{tabular}

\section{CONCLUSION}

Nowadays, the companies are confronted with all types of business rules. Regulatory institutions, business units, customers, competitors and the 
conditions of the market generate business rule changes all the time, which are translated in more business rules. The companies need fast reaction to the changes of the customers' demands. Businesses try to support quite individualized relationships with growing numbers of customers and partners for products and services with growing complexity.

In the context of public administrations, there are portions of business logic that are very static, normally supported by legacy systems, with severe constraints in terms of laws, policies and procedures. On the other hand there are portions of business logic that should be dynamic to improve the effectiveness of the public administration. Unfortunately, many of the government applications are rigid because their business rules are totally "lost" in the generated code and it is difficult to maintain them. The consequence is that the governments have difficulties in being agile on answering to changes demanded by citizens, enterprises and the government itself. The proposed business rule engine aims to contribute to the resolution of this problem. It considers that the business rules must be structured, classified and properly related with well-defined parts of the generated code, which, in this case, are defined as Web services or business components.

This proposal manages successfully, at least partially, the three main challenges related to the business rules engines initiatives. The first challenge, the difficulty in the capture and formalization of business rules, which are "lost" in the specifications of requirements is minimized once the pre-conditions, pos-conditions are directly structured in the business rule statement. The obligation and prohibition restrictions are managed by the Jess backward-chaining mechanism, once the action will be dispatched only if the pre-conditions are satisfied. The second challenge, the relationship of business rules with several use cases can be structured through the use of rule set concept, where for each use case is associated the necessary rule sets to deal with that specific use case. Finally, the third challenge, which is the weakness in the combined execution of business rules and Web services is successfully accomplished. The first prototype of this BRE, designed as an extension of the Jess rule engine, is indicating that the proposed approach really annuls that weakness.

Further research is needed in order to formalize the relationship structure of business rules and use cases. Also is needed to focus on other formalization aspects of business rules "lost" in the specifications, such as UML alternative flows, OCL restrictions and derived attributes. Another issue that has to considered is to turn this proposal adherent to other standardization efforts, such as SWRL. 


\section{REFERENCES}

1. Standard based Framework, Cuecent BPMS, http://www.bahwancybertek.com/cuecentBpms.html, accessed in 12/05/2005.

2. Sinur, James, VP Gartner - The Rules Resurrection Is Upon Us, The Business Rules Forum, Semantic Arts Inc., 2003

3. Chapin, Donald - Capturing the Language of Business, Business Semantics Limited, 2002

4. Ross, Ronald G. - Serving Up Knowledge in: Principles of Business Rule Approach, Addison-Wesley, 2003

5. Blaze Advisor, Fair Isaac, http://www.fairisaac.com/Fairisaac/Solutions/Product+Index/Blaze+Advisor/, 15/05/05

6. CleverPath Aion, Business Rules Expert, Computer Associates, http://www3.ca.com/Solutions/Product.asp?ID=250, accessed in 15/05/05

7. BRS RuleTrack, Business Rule Solutions LLC, http://www.brsolutions.com/prod_support.php, accessed in 15/05/05

8. Ross, Ronald G., The Business Rule Book: Classifying, Defining and Modeling Rules, Version 4.0, Business Rule Solutions, 1997

9. eGOIA - Electronic Government Innovation and Access, http://www.egoia.info/, accessed in 14/05/2005.

10. (a) LIS : Alliance for the Information Society, http://europa.eu.int/comm/europeaid/projects/alis/index_en.htm, accessed in 14/05/2005.

11. BSBR - bei/2005-03-01, Version: 7.0, 2005

12. Ross, Ronald G., Principles of Business Rule Approach, 77-80, Addison-Wesley, 2003

13. Burlton, Roger - From Strategic Intent to Requirements Definition, Business Rules Forum, 2004

14. Zachman, John, Business Rules and the Framework, http://semarts.com.decisivenet.com/DesktopModules/ViewArticle.aspx?ArticleID $=723 \&$ $\underline{\text { mid }=3476,2003}$

15. Sinur, J. - Gartner, WITH-19-9972, Notices of Research, 2003.

16. Business Semantics of Business Rules RFP - br/2003-06-03, 2003

17. BRG, The Business Rules Manifesto, http://www.businessrulesgroup.org/brmanifesto.htm, accessed in 15/05/2005

18. W3C, Semantic Web Rule Language (SWRL), 2005

19. Haley, Haley Enterprise, http://www.haley.com/0424686433342466/THE.html,

20. Jrules, ILOG, http://www.ilog.com, accessed in 14/05/2005

21. VALENS, LibRT, www.LibRT.com, accessed in 14/05/2005

22. Corticon Decision Management, Corticon, http://www.avoka.com/bpm/corticon.shtml, accessed in 14/05/2005

23. Friedman-Hill, Emest, Jess in Action, Manning Publication Co., 2003

24. OFBiz Rule Engine, Open For Business Project, http.//www.ofbiz.org/, accessed in $15 / 05 / 2005$

25. Mandarax, The Mandarax Project, http://mandarax.sourceforge.net, accessed in 15/05/2005

26. Drools, Implementation of Forgy's Rete algorithm, http://drools.org/, accessed in $15 / 05 / 2005$

27. Jena 2, A Semantic Web Framework, http://www.hpl.hp.com/semweb/jena2.htm, accessed in 15/05/2005

28. Chisholm, Malcolm, How to Build a Business Rules Engine, Elsevier, Morgan Kauhfmann Publishers, 2004 